If you wish to distribute this article to others, you can order high-quality copies for your colleagues, clients, or customers by clicking here.

Permission to republish or repurpose articles or portions of articles can be obtained by following the guidelines here.

The following resources related to this article are available online at www.sciencemag.org (this information is current as of September 25, 2014 ):

Updated information and services, including high-resolution figures, can be found in the online version of this article at:

http://www.sciencemag.org/content/328/5980/832.full.html

This article cites 12 articles, 8 of which can be accessed free:

http://www.sciencemag.org/content/328/5980/832.full.html\#ref-list-1

This article has been cited by 2 articles hosted by HighWire Press; see:

http://www.sciencemag.org/content/328/5980/832. full.html\#related-urls

This article appears in the following subject collections:

Ecology

http://www.sciencemag.org/cgi/collection/ecology 
molecular functions of individual components of the assembly machinery. So far, three major mechanisms have been proposed for insertion of the $\beta$-barrel precursors into the outer membrane. BamA and Sam50, which are $\beta$-barrel proteins themselves, form channels $(9,14)$, but it is not yet clear whether the precursors are inserted into a pore formed within a monomer or whether oligomeric forms of BamA and Sam50 form a channel. A third possibility is that the precursor proteins are not inserted into the outer membrane via a protein channel, but that BAM/SAM function as a scaffold that facilitates insertion of $\beta$-barrel proteins at the protein-lipid interface.

What are the functions of the further components of the $\beta$-barrel assembly pathway? When Hagan et al. altered the composition of the accessory lipoproteins in their reconstituted system; they found that most subcomplexes were unstable. The stability of two subcomplexes - BamAB and BamACDEwas similar to that of the full BAM complex, but they had low activity in $\beta$-barrel assembly upon reconstitution into liposomes. Thus, all four accessory lipoproteins are required for full activity of the BAM complex. The results of Hagan et al. further suggest that multiple copies of SurA bind to a precursor protein and that the chaperone-precursor complex directly delivers the $\beta$-barrel polypeptides to the outermembrane assembly machinery in a foldingcompetent state (8). The authors found no evidence for an external energy source driving precursor transfer and insertion into the outer membrane. The transport pathway may be driven by the free energy released during folding and insertion of the $\beta$ barrels into the lipid phase of the outer membrane.

The core processes of $\beta$-barrel biogenesis have been conserved during evolution (1), but the machineries acquired further functions. The mitochondrial SAM complex is not only required for the biogenesis of $\beta$-barrel proteins, but is also a dynamic platform for the assembly of $\alpha$-helical proteins of the outer membrane. Several forms of the SAM complex, differing in subunit composition, serve distinct functions in the biogenesis of different classes of precursor proteins (12). The SAM complex is associated with a multifunctional organizing center that is involved in lipid transport, maintenance of mitochondrial shape, and the connection of mitochondria to the endoplasmic reticulum $(10-12,15)$. Future studies will address whether the BAM complex is dedicated to $\beta$-barrel assembly only or whether it may play further roles in outer-membrane biogenesis. The reconstruction of the BAM complex as a stable, active, and homogeneous complex by Hagan et al. will also greatly aid in solving the high-resolution structure of an outer-membrane assembly machinery.

\section{References}

1. E. Schleiff, ]. Soll, EMBO Rep 6, 1023 (2005).

2. C. L. Hagan et al., Science 328, 890 (2010); published online 8 April 2010 (10.1126/science.1188919).

3. R. Voulhoux, M. P. Bos, ]. Geurtsen, M. Mols, J. Tommassen, Science 299, 262 (2003).

4. T. Wu et al., Cell 121, 235 (2005).

5. N. Wiedemann et al., Nature 424, 565 (2003).

6. W. Neupert, ]. M. Herrmann, Annu. Rev. Biochem. 76 723 (2007)

7. N. C. Chan, T. Lithgow, Mol. Biol. Cell 19, 126 (2008).

8. J. G. Sklar, T. Wu, D. Kahne, T. J. Silhavy, Genes Dev. 21, 2473 (2007).

9. S. Kutik et al., Cell 132, 1011 (2008).

10. K. Yamano, S. Tanaka-Yamano, T. Endo, EMBO Rep. 11, 187 (2010).

11. J. G. Wideman et al., Mol. Biol. Cell 10.1091/ mbcE09-10-0844 (2010).

12. N. Thornton et al., J. Mol. Biol. 396, 540 (2010).

13. D. M. Walther, D. Papic, M. P. Bos, ]. Tommassen, D. Rapaport, Proc. Natl. Acad. Sci. U.S.A. 106, 2531 (2009)

14. V. Robert et al., PLoS Biol. 4, e377 (2006).

15. B. Kornmann et al., Science 325, 477 (2009).

10.1126/science. 1190507

\title{
Are Lizards Toast?
}

\author{
Raymond B. Huey, ${ }^{1}$ Jonathan B. Losos, ${ }^{2}$ Craig Moritz $^{3}$
}

$\mathrm{L}$ izards should be relatively invulnerable to warming: They are very good at evading thermal stress, tolerate high body temperatures, and resist water loss. Nevertheless, on page 894 of this issue, Sinervo et al. (1) document extinctions of lizard populations on five continents and argue that global warming is responsible. They use a simple biological model, validated against observed extinctions, to predict that warming will drive almost $40 \%$ of all global lizard populations extinct by 2080 . If their prediction is even close to correct, lizards may be "the new amphibians" (2) in a race toward extinction.

A stark result for a genus of lizards in México leads off their paper: $12 \%$ of 200 previously validated Sceloporus populations (all with intact habitats) went extinct in recent

${ }^{1}$ Department of Biology, University of Washington, Seattle, WA 98195, USA. ${ }^{2}$ Museum of Comparative Zoology, Harvard University, Cambridge, MA 02138, USA. ${ }^{3}$ Museum of Vertebrate Zoology, University of California, Berkeley, CA 94720, USA.E-mail: hueyrb@uw.edu decades. Moreover, extinction probability was correlated with magnitude of warming at that site in spring, but not in other seasons. This correlation suggests that extinction is driven by energetic shortfalls during spring (when reproductive energy demands are highest), rather than by summer heat stress. Lizard natural history is instructive here: On hot days, lizards seek cooler refuges, such as burrows. With warming, lizards will spend longer periods in refuges, reducing foraging time, such that net energy gain becomes insufficient for reproduction; extinction ensues.

To test this mechanistic hypothesis, Sinervo et al. examined four $S$. serrifer populations, two of which have recently gone extinct (see the first figure). Using field estimates of maximum available body temperatures of lizards (operative temperatures) at these sites in spring and of body temperatures acceptable for activity, they predicted the number of hours per day that operative temperatures exceeded a lizard's thermal preferences, thus forcing retreat (see the second figure). At sites
Warming is held responsible for a rash of extinctions of global lizard populations.

where the lizards are now extinct, predicted time restrictions exceeded 3.85 hours; but at sites where lizards persist, predicted restrictions were shorter. Sinervo et al. then used air temperature data from weather stations to estimate time restrictions at all Méxican sites. Sceloporus populations with predicted restrictions above 3.85 hours in spring had higher extinction rates than did populations with shorter restrictions.

To predict future extinctions, Sinervo et $a l$. applied their history-validated approach to current and future warming scenarios across the globe, using 1216 lizard populations on four continents. First, by resurveying known lizard populations and conducting literature surveys, they detected many extinctions; for example, $21 \%$ of Madagascar lizard populations in nature reserves have gone extinct. Estimated activity-time restrictions (with critical thresholds tuned to the thermal biology of each lizard family) effectively predicted populations that had gone extinct. Based on these data, the authors estimate that by 2080 , 
